\title{
Impact of intervention on metabolic outcomes among dropouts with type 2 diabetes
}

\section{Laine, Merja K.}

2018-03

Laine, M K, Kauppila , T, Honkasalo, M , Raina , M \& Eriksson, J G 2018 , ' Impact of intervention on metabolic outcomes among dropouts with type 2 diabetes ' , Advances in Medical Sciences, vol. 63 , no. 1, pp. 5-8 . https://doi.org/10.1016/j.advms.2017.05.003

http://hdl.handle.net/10138/297832

https://doi.org/10.1016/j.advms.2017.05.003

publishedVersion

Downloaded from Helda, University of Helsinki institutional repository.

This is an electronic reprint of the original article.

This reprint may differ from the original in pagination and typographic detail.

Please cite the original version. 


\title{
Impact of intervention on metabolic outcomes among dropouts with type 2 diabetes
}

\author{
Merja K. Laine ${ }^{\mathrm{a}, \mathrm{b}, *}$, Timo Kauppila ${ }^{\mathrm{a}, \mathrm{b}}$, Mikko Honkasalo ${ }^{\mathrm{a}, \mathrm{c}}$, Marko Raina ${ }^{\mathrm{b}}$, \\ Johan G. Eriksson a,d \\ a Department of General Practice and Primary Healthcare, University of Helsinki and Helsinki University Hospital, Helsinki, Finland \\ b Vantaa Health Center, Vantaa, Finland \\ ${ }^{\mathrm{c}}$ Nurmijärvi Health Center, Nurmijärvi, Finland \\ ${ }^{\mathrm{d}}$ Folkhälsan Research Center, Helsinki, Finland
}

\section{A R T I C L E I N F O}

\section{Article history:}

Received 4 November 2016

Accepted 21 May 2017

Available online $\mathrm{xxx}$

Keywords:

Type 2 diabetes

Dropout

Metabolic profile

Primary health care

\begin{abstract}
A B S T R A C T
Purpose: The aim of this study was to evaluate the effect of an individual intervention given by health care professionals to dropouts with type 2 diabetes (T2D) on their metabolic profile.

Materials/methods: In 2010, we identified 356 T2D dropouts in Vantaa Health Centre, Finland. At the baseline visit the participants' status was assessed including laboratory tests. Diabetes counseling was given, and drug treatment was enhanced when needed. The follow-up visit was performed 13 to 30 months later including the same assessments as performed at the baseline visit. The dropouts who attended the follow-up visit formed the study group. One third $(n=115)$ of the dropouts participated in the follow-up visit.

Results: The study participants (mean age 61.4 years) were older than the non-participants (mean age 58.5 years $)(p=0.009)$. After the intervention the proportion of participants with hemoglobin $A 1 c \geq 9 \%$ $(75 \mathrm{mmol} / \mathrm{mol})$ decreased from $15.5 \%$ to $5.2 \%(\mathrm{p}=0.004)$. Improvements were also observed in general in hemoglobin A1c, from $6.6 \%(49 \mathrm{mmol} / \mathrm{mol})$ to $6.3 \%(45 \mathrm{mmol} / \mathrm{mol})(\mathrm{p}=0.001)$, in total cholesterol, from $4.9 \mathrm{mmol} / \mathrm{l}$ to $4.5 \mathrm{mmol} / \mathrm{l}(\mathrm{p}=0.011$ ), in low-density lipoprotein cholesterol, from $2.9 \mathrm{mmol} / \mathrm{l}$ to $2.6 \mathrm{mmol} /$ $\mathrm{l}(\mathrm{p}=0.015)$ and in diastolic blood pressure, from $90 \mathrm{mmHg}$ to $84 \mathrm{mmHg}(\mathrm{p}=0.001)$.

Conclusions: Dropouts with T2D were difficult to bring back to the public health care system, especially men under the age of 60 years. Dropouts who participated in the intervention showed improvements in several metabolic outcomes.
\end{abstract}

(c) 2017 Medical University of Bialystok. Published by Elsevier B.V. All rights reserved.

\section{Key messages}

- Dropouts with T2D are difficult to bring back to diabetes care.

- Men younger than 60 years seem to be at high-risk to drop out from public diabetes care.

- An individual intervention improved several metabolic outcomes.

Abbreviations: BP, blood pressure; $\mathrm{HbA}_{1 \mathrm{c}}$, hemoglobin $\mathrm{A} 1 \mathrm{c} ; \mathrm{HDL}$, high, density lipoprotein; IRQ interquartile range; LDL, low-density lipoprotein; SD, standard deviation; T2D, type 2 diabetes.

* Corresponding author at: Department of General Practice and Primary, Health Care, University of Helsinki and Helsinki University Hospital, Tukholmankatu 8, B, PL 20, 00140 Helsinki, Finland.

E-mail addresses: merja.k.laine@helsinki.fi (M.K. Laine), timo.kauppila@fimnet.fi (T. Kauppila), mikko.honkasalo@nurmijarvi.fi

(M. Honkasalo), marko.raina@apotti.fi (M. Raina), johan.eriksson@helsinki.fi (J.G. Eriksson).

\section{Introduction}

Globally, the burden of type 2 diabetes (T2D) is increasing [1]. The general treatment goal is to prevent acute complications, reduce the risk of long-term diabetic complications including micro- and macro-vascular complications as well as to ensure an optimal quality of life [2]. Treatment of T2D involves both lifestyle modifications and drug treatment.

A proportion of the patients with T2D does not attend diabetes clinics as prescribed by the health care personnel. The underlying reasons for dropout differ, e.g. long distance to the clinic, multi morbidity, treatment goals requiring lifestyle changes, patients' age and gender [3,4]. Potentially, these dropouts are exposed to an increased risk for diabetic complications further influencing their quality of life and increasing the costs of diabetes treatment for society. 
In the public primary health care center of the city of Vantaa, Finland, we investigated the phenomenon of dropout. In 2009, every tenth patient with T2D was a 'dropout' from the public primary diabetes care system [5]. Among these patients, the level of hemoglobin $\mathrm{A} 1 \mathrm{c}\left(\mathrm{HbA}_{1 \mathrm{c}}\right)$ was satisfactory whereas low-density lipoprotein (LDL) cholesterol and blood pressure (BP) were nonoptimal [5]. Our aim was to attach these dropouts back to the diabetes care system and enhance their treatment when needed. The purpose of this study was to evaluate the effect of a 'real-life' intervention given by health care professionals to the dropouts with T2D on their metabolic profile.

\section{Methods}

\subsection{Study population}

A detailed description of the patients with T2D, who were dropouts from diabetes care within the public primary health care system, has been published recently [5]. Briefly, we identified dropouts with T2D aged $18-80$ years from diabetes care in public primary health care by using computer aided search from an electric patient record system (Finstar) in the Eastern districts of the city of Vantaa, Finland. Patients fulfilled the criteria for dropout, if they during the years 2005-2009 had an ICD-10 code including an E11 code or if they used T2D specific medication and they had not contacted the public primary health care system during the year 2009. All together, we were able to identify 356 dropouts (10.3\% of patients with T2D in Eastern Vantaa). Trained diabetes nurses contacted and interviewed the dropouts by telephone, and invited them to a baseline outpatient and laboratory visit within the public health care system. Of the contacted dropouts, $66.3 \%$ (of whom $60.6 \%$ were men and $39.4 \%$ were women) came to the baseline visit and $84.8 \%$ (of whom $58.9 \%$ were men and $41.1 \%$ women) had laboratory tests taken.

The follow-up visit took place 13 to 30 months after the baseline visit either as a visit to a trained diabetes nurse or to a general practitioner at the primary health care center. Those dropouts, who came to the follow-up visit, composed the study group in this present study $(n=115)$. Fig. 1 shows the study flowchart.

\subsection{Measurements}

At the baseline visit the following characteristics were recorded: age, gender, height, weight, $\mathrm{BP}$, duration of $\mathrm{T} 2 \mathrm{D}$, signs of proteinuria and/or retinopathy, and diabetes medication as well as marital status, occupation and comorbidities based on ICD-10 diagnoses. Further, at baseline the following laboratory tests were performed $\mathrm{HbA}_{1 \mathrm{c}}$, total cholesterol, $\mathrm{LDL}$-cholesterol, high-density lipoprotein (HDL) - cholesterol and triglycerides. Of the dropouts, a detailed description of the baseline characteristics of the dropouts with T2D has been published previously [5]. At the baseline visit the intervention was given in the following way: trained diabetes nurses counseled the participants individually aiming at better self-management behavior and if needed, the general practitioners of the health care center enhanced diabetes drug treatment.

At the follow-up visit the participants' weight; blood pressure and diabetes medication were recorded. Further, the participants were asked to visit the laboratory for the same laboratory tests as performed at the baseline visit.

The ethics committee of the Hospital District of Helsinki and Uusimaa, and the health authority of the Vantaa city have approved the study.

Statement of Informed Consent: This study is an observational retrospective register based cohort study based on an electric patient record system; we assessed the effects of the work performed by the community primary health care nurses and general practitioners. The investigators 'per se' did not contact the dropouts. According to the ethics committee of the Hospital District of Helsinki and Uusimaa, and the health authority of the city of Vantaa the patients do not need to have the Statement of Informed Consent.

\subsection{Statistical analysis}

Data are reported as percentage (number) or mean (standard deviations [SD]) or median (interquartile range [IRQ]). Percentage differences were tested using cross-tabulation and Chi-Square test or McNemar test. Comparisons were carried out by Mann-Whitney $U$ test or by independent samples T-test between the study participants and the non-participants. Comparisons were carried out by Wilcoxon signed rank test or paired samples T-test was used when comparing the results from the baseline and the follow-up visit. Statistical analyses were carried out using IBM SPSS, version 22.0 (IBM, Armonk, NY, USA). A p-value of less than 0.05 was considered statistically significant.

\section{Results}

About one third $(n=115)$ of the dropouts participated in the follow-up visit. The characteristics of the study participants and non-participants are presented in Table 1. For the classification of the dropouts' glycemic control $\left(\mathrm{HbA}_{1 \mathrm{c}}\right.$ level), the following

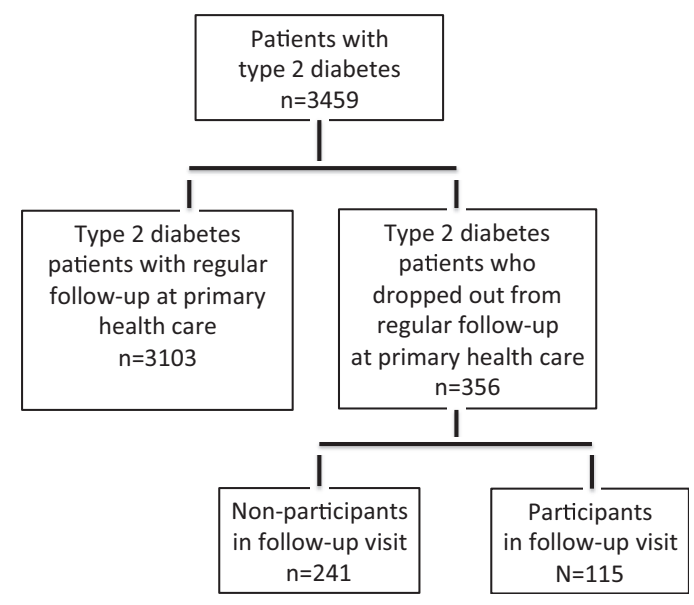

Fig. 1. Study flowchart. 
Table 1

Baseline characteristics of the study participants and non-participants.

\begin{tabular}{|c|c|c|c|c|c|c|c|c|c|}
\hline & \multicolumn{3}{|c|}{ Participants, $N=115$} & \multicolumn{3}{|c|}{ Non-participants, $\mathrm{N}=241$} & \multicolumn{3}{|c|}{ P-value } \\
\hline & All & Males & Females & All & Males & Females & All & Males & Females \\
\hline Study subjects n, (\%) & $115(100)$ & $62(53.9)$ & $53(46.1)$ & $241(100)$ & $152(63.1)$ & 89 (36.9) & & & \\
\hline Age, years & $61.4(9.4)$ & $62.7(8.2)$ & $59.9(10.5)$ & $58.5(10.0)$ & $58.6(9.2)$ & $58.2(11.2)$ & 0.009 & 0.003 & 0.392 \\
\hline T2D duration*, years & $6.0(8.0)$ & $7.0(7.0)$ & $4.5(7.0)$ & $5.0(5.0)$ & $5.0(6.0)$ & $6.0(6.0)$ & 0.276 & 0.027 & 0.374 \\
\hline BMI, $\mathrm{kg} / \mathrm{m}^{2}$ & $32.4(6.2)$ & $31.4(5.8)$ & $33.7(6.6)$ & $31.6(6.6)$ & $30.8(5.9)$ & $32.9(7.5)$ & 0.147 & 0.443 & 0.270 \\
\hline Hemoglobin A1c*, \% & $6.6(1.7)$ & $6.7(1.5)$ & $7.3(2.1)$ & $6.4(1.9)$ & $6.4(1.8)$ & $6.4(1.8)$ & 0.616 & 0.490 & 0.921 \\
\hline Total cholesterol*, mmol/l & $4.7(1.7)$ & $4.5(1.7)$ & $5.0(1.9)$ & $4.8(1.4)$ & $4.7(1.5)$ & $5.0(1.7)$ & 0.856 & 0.435 & 0.832 \\
\hline LDL-cholesterol*, mmol/l & $2.8(1.3)$ & $2.5(1.3)$ & $3.0(1.5)$ & $2.8(1.4)$ & $2.7(1.3)$ & $3.0(1.4)$ & 0.483 & 0.179 & 0.939 \\
\hline HDL-cholesterol*, mmol/l & $1.2(0.3)$ & $1.3(0.4)$ & $1.2(0.3)$ & $1.2(0.5)$ & $1.2(0.4)$ & $1.4(0.5)$ & 0.339 & 0.058 & 0.336 \\
\hline Triglycerides*, mmol/l & $1.8(1.3)$ & $1.5(1.3)$ & $1.8(1.3)$ & $1.6(1.0)$ & $1.6(1.1)$ & $1.6(0.7)$ & 0.416 & 0.673 & 0.095 \\
\hline Proteinuria $n,(\%)$ & $25(19.7)$ & $19(35.2)$ & $6(19.4)$ & $33(26.2)$ & $18(21.7)$ & $15(34.9)$ & 0.607 & 0.082 & 0.144 \\
\hline Retinopathy n, (\%) & $25(29.4)$ & $19(35.2)$ & $6(19.4)$ & $33(26.2)$ & $18(21.7)$ & $15(34.9)$ & 0.607 & 0.082 & 0.144 \\
\hline Systolic BP, mmHg & $147(21.7)$ & $144(18.9)$ & $151(24.7)$ & $145(22.7)$ & $146(21.9)$ & $144(24.2)$ & 0.571 & 0.632 & 0.218 \\
\hline Diastolic BP, mmHg & $88(10.8)$ & $85(9.9)$ & $90(11.5)$ & $86(12.4)$ & $87(12.3)$ & $84(12.4)$ & 0.277 & 0.492 & 0.017 \\
\hline
\end{tabular}

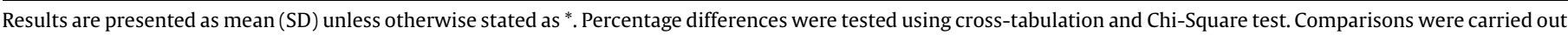

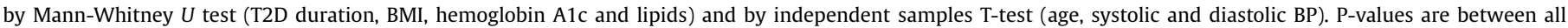
participants vs non-participants, between males participants vs non-participants, and between females participants vs non-participants.

${ }^{*}$ Median (interquartile range).

$\mathrm{T} 2 \mathrm{D}=$ type 2 diabetes; $\mathrm{BMI}=$ body mass index; $\mathrm{LDL}=$ low density lipoprotein; $\mathrm{HDL}=$ high density lipoprotein; $\mathrm{BP}=\mathrm{blood}$ pressure; SD=standard deviation .

grouping was used $\mathrm{HbA}_{1 \mathrm{c}}<7 \% \quad(53 \mathrm{mmol} / \mathrm{mol}), \quad \mathrm{HbA}_{1 \mathrm{c}} \quad 7-9 \%$ ( $53 \mathrm{mmol} / \mathrm{mol}$ to $75 \mathrm{mmol} / \mathrm{mol})$ and $\mathrm{HbA}_{1 \mathrm{c}} \geq 9 \%(75 \mathrm{mmol} / \mathrm{mol})$. No differences were observed between the participants and the non-participants in $\mathrm{HbA}_{1 \mathrm{c}}$ levels. The non-participants were prescribed sulfonylureas/glinides more often than the participants $(\mathrm{p}=0.040)$, but no significant differences were observed in relation to prescription of other diabetes drugs. There were no differences in marital status, occupation nor in comorbidities between the participants and the non-participants.

The effect of the intervention on BMI, $\mathrm{HbA}_{1 \mathrm{c}}$, lipids and $\mathrm{BP}$ is presented in Table 2 . At the baseline visit $15.5 \%$ of the participants had $\mathrm{HbA}_{1 \mathrm{c}} \geq 9 \%$ (75 mmol/mol) and the corresponding percentage at the follow-up visit was $5.2 \%(\mathrm{p}=0.004)$. During the follow-up period more participants were prescribed metformin $(67.0 \%$ vs $83.5 \%, \mathrm{p}<0.001$ ), basal insulin (8.7\% vs $20.9 \%, \mathrm{p}<0.001)$ and DPP4 inhibitors ( $3.5 \%$ vs $30.4 \%, \mathrm{p}<0.001$ ) compared with the situation at baseline. The prescription of sulfonylureas/glinides decreased significantly ( $24.3 \%$ vs $13.9 \%, \mathrm{p}=0.004)$. More information on the changes in diabetes drug treatment as a consequence of the intervention is presented in Supplementary material, Table 1.

\section{Discussion}

According to our study findings, it was possible to bring back only one third of the dropouts with T2D to the diabetes treatment system. Especially, dropouts under 60 years of age were difficult to bring back. However, those who participated and who were successfully brought back to the system, showed improvements in $\mathrm{HbA}_{1 \mathrm{c}}$ level, total and LDL-cholesterol, and diastolic BP. In addition, female participants showed improvements on triglycerides and systolic BP after the intervention.

Previous studies focusing upon the phenomenon of T2D dropouts have focused primarily on relapse prevention or characterization of the dropouts, less on the possibility to bring them back to the health care system. To the best of our knowledge, studies assessing feasibility and possibility to bring back dropouts with any chronic disease to the public health care system are rare. According to our study findings, dropouts with T2D were challenging to bring back to the health care system: even though the diabetes nurse invited them personally, only one third attended the follow-up visit 13-30 months after the baseline visit. The non-participants were younger than the participants supporting findings from previous communal based studies among dropouts [4-7]. We did not observe any differences in sex, duration of T2D or BMI between the participants and non-participants. These findings are in line with most previous studies on diabetes dropouts [3,5,6,8-10]. Further, we did not find any differences between the groups in $\mathrm{HbA}_{1 \mathrm{c}}$, lipids, $\mathrm{BP}$, signs of nephropathy or retinopathy, comorbidities, occupation or marital status. Previous study findings focusing upon these aforementioned factors have been inconsistent [10]. In relation to diabetes medication, we observed that the non-participants were more often prescribed

Table 2

Effect of intervention on BMI, hemoglobin A1c, lipids and BP among the study participants.

\begin{tabular}{|c|c|c|c|c|c|c|c|c|c|}
\hline & \multicolumn{3}{|c|}{ Before, $n=115$} & \multicolumn{3}{|c|}{ After, $n=115$} & \multicolumn{3}{|c|}{ P-value } \\
\hline & All & Males, $\mathrm{n}=62$ & Females, $n=53$ & All & Males, $\mathrm{n}=62$ & Females, $\mathrm{n}=53$ & All & Males & Females \\
\hline BMI*, $\mathrm{kg} / \mathrm{m}^{2}$ & $32.4(5.4)$ & $33.5(6.5)$ & $32.9(4.7)$ & $32.2(6.4)$ & $30.4(6.7)$ & $34.4(5.5)$ & 0.339 & 0.183 & 0.975 \\
\hline Hemoglobin A1c*, \% & $6.6(1.7)$ & $6.7(1.5)$ & $6.4(2.1)$ & $6.3(1.3)$ & $6.4(1.3)$ & $6.2(1.5)$ & 0.001 & 0.013 & 0.023 \\
\hline Total cholesterol*, mmol/l & $4.9(1.1)$ & $4.8(1.1)$ & $4.9(1.2)$ & $4.5(1.1)$ & $4.5(1.1)$ & $4.5(1.1)$ & 0.011 & 0.169 & 0.018 \\
\hline LDL-cholesterol*, mmol/l & $2.9(0.9)$ & $2.8(0.9)$ & $3.1(0.9)$ & $2.6(0.9)$ & $2.6(0.8)$ & $2.7(0.9)$ & 0.015 & 0.305 & 0.012 \\
\hline HDL-cholesterol*, mmol/l & $1.3(0.3)$ & $1.2(0.3)$ & $1.3(0.4)$ & $1.2(0.3)$ & $1.2(0.3)$ & $1.3(0.4)$ & 0.301 & 0.849 & 0.171 \\
\hline Triglycerides*, mmol/l & $2.0(1.2)$ & $2.2(1.4)$ & $1.6(1.2)$ & $1.7(1.3)$ & $2.0(1.9)$ & $1.6(1.0)$ & 0.355 & 0.476 & 0.021 \\
\hline Systolic BP, mmHg & $149(22.1)$ & $144(21.3)$ & $155(22.1)$ & $143(20.3)$ & $141(16.6)$ & 146 (23.9) & 0.069 & 0.510 & 0.042 \\
\hline Diastolic BP, mmHg & $90(11.4)$ & $86(10.3)$ & $94(11.6)$ & $84(10.8)$ & $82(10.5)$ & $86(11.0)$ & 0.001 & 0.036 & 0.015 \\
\hline
\end{tabular}

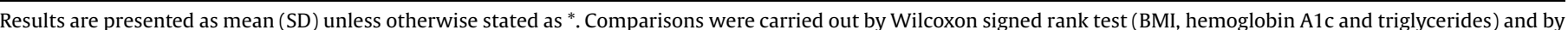

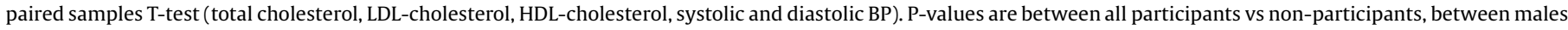
participants vs non-participants, and between females participants vs non-participants.

${ }^{*}$ Median (interquartile range)

$\mathrm{BP}=$ blood pressure; $\mathrm{BMI}=$ body mass index; $\mathrm{LDL}=$ low density lipoprotein; HDL = high density lipoprotein; $\mathrm{SD}=\mathrm{standard}$ dev 
sulfonylureas/glinides than the participants. Some studies have shown a low dropout rate in patients with insulin treatment $[3,6]$. Overall, the existing literature of T2D dropout is inconsistent partly explained by differences in defining dropouts', sample sizes and study designs [10].

After the intervention, the level of $\mathrm{HbA}_{1 \mathrm{c}}$ improved significantly, although the baseline level of $\mathrm{HbA}_{1 \mathrm{c}}$ was already at a satisfactory level. Importantly, a proportion of patient with high baseline $\mathrm{HbA}_{1 \mathrm{c}}$ levels showed marked improvements. The risk for any diabetes related complication increases notably when $\mathrm{HbA}_{1 \mathrm{c}}$ level is over nine per cent [11]. One explanatory factor for the improvement in $\mathrm{HbA}_{1 \mathrm{c}}$ is enhancements in diabetes medication: more prescriptions of metformin, basal insulin and incretin-based drugs were observed. In addition, the participants received counseling by the diabetes nurse for better self-management behavior and diabetes treatment. To achieve optimal $\mathrm{HbA}_{1 \mathrm{c}}$ level, both active selfmanagement and tailored drug treatment are needed $[12,13]$. The present intervention also improved significantly the participants' lipid metabolism. A beneficial effect of the intervention was also seen in diastolic blood pressure. The intervention showed no effect on degree of adiposity.

According to Finnish Current Care Guidelines, patients with T2D should be treated holistically and the treatment targets should be individually tailored [2]. The holistic treatment includes evaluation and management of lifestyle factors, glycaemia, dyslipidemia, blood pressure and consideration for antiplatelet therapy [2]. With an optimal treatment of T2D it is possible to decrease the risk of micro- and macrovascular complications and mortality [14]. This kind of multifactorial treatment is also cost-effective [15].

\subsection{Study limitations}

We acknowledge some limitations to our study. Due to the nature of the dropout phenomenon the dropout rate was high and the dropouts in the present study had no control group. Some of those that we classified as dropouts may have their T2D treatment in the private sector or in the occupational health care setting. Further, all our participants were of European ancestry, which may influence the generalizability of the results. Data on dropouts' lifestyle factors, including physical activity, dietary or sleeping habits, smoking and alcohol consumption, as well as other medication than diabetes medication were not available. These factors may influence the results and should be addressed in future research.

\subsection{Implication for clinical practice}

It is important to identify diabetics dropouts with poor metabolic condition. Among those successfully brought back to diabetes care, intervention seems to improve metabolic outcomes.

\section{Conclusions}

The dropouts were challenging to bring back to diabetes care, especially men below 60 years of age. The dropouts who participated in the intervention showed improvements in $\mathrm{HbA}_{1 \mathrm{c}}$, BP and lipid levels.

\section{Conflict of interests}

The authors declare no conflict of interests.

\section{Financial resources}

The Hospital District of Helsinki and Uusimaa awarded a research grant for this study.

\section{Acknowledgement}

We would like to thank diabetes nurses of Vantaa city for contacting the dropouts.

\section{Appendix A. Supplementary data}

Supplementary data associated with this article can be found, in the online version, at http://dx.doi.org/10.1016/j. advms.2017.05.003.

\section{References}

[1] Lim SS, Vos T, Flaxman AD, et al. A comparative risk assessment of burden of disease and injury attributable to 67 risk factors and risk factor clusters in 21 regions, 1990-2010: a systematic analysis for the Global Burden of Disease Study. Lancet 2010;380:2224-60.

[2] ADA Standards of medical care in diabetes-2015: summary of revisionss. Diabetes Care 2015(Suppl. 38) S4-S003.

[3] Graber AL, Davidson P, Brown AW, et al. Dropout and relapse during diabetes care. Diabetes Care 1992;15:1477-83.

[4] Fullerton B, Erler A, Pöhlmann B, et al. Predictors of dropout in the German disease management program for type 2 diabetes. BMC Health Serv Res 201212: 8-6963-12-8.

[5] Kauppila T, Laine MK, Honkasalo M, et al. Contacting dropouts from type 2 diabetes care in public primary health care: description of the patient population. Scand J Prim Health 2016, doi:http://dx.doi.org/10.1080/ 02813432.2016 .1207144$.

[6] Simmons D, Fleming C. Prevalence and characteristics of diabetic patients with no ongoing care in South Auckland. Diabetes Care 2000;23:1791-3.

[7] Tsujimura Y, Takahashi Y, Ishizaki T, et al. Predictors of hyperglycaemic individuals who do not follow up with physicians after screening in Japan: a cohort study. Diabetes Res Clin Pract 2014;105:176-84.

[8] Benoit SR, Ji MR, Fleming R, et al. Predictors of dropouts from a San Diego diabetes program: a case control study. Prev Chron Dis 2004;1:A10.

[9] Sone H, Kawai K, Takagi H, et al. Outcome of one-year of specialist care of patients with type 2 diabetes: a multi-center prospective survey (JDDM 2). Intern Med 2006;45:589-97.

[10] Gucciardi E. A systematic review of attrition from diabetes education services: strategies to improve attrition and retention research. Can J Diabetes 2008;32:53-65.

[11] Stratton IM, Adler AI, Neil HA, et al. Association of glycaemia with macrovascular and microvascular complications of type 2 diabetes (UKPDS 35): prospective observational study. BMJ 2000;321:405-12.

[12] Deakin T, McShane CE, Cade JE, et al. Group based training for selfmanagement strategies in people with type 2 diabetes mellitus. Cochrane Database Syst Rev 2005;(2):CD003417.

[13] Houle J, Beaulieu MD, Chiasson JL, et al. Glycaemic control and selfmanagement behaviours in Type 2 diabetes: results from a 1-year longitudinal cohort study. Diabet Med 2015;32:1247-54.

[14] Gaede P, Lund-Andersen $\mathrm{H}$, Parving $\mathrm{HH}$, et al. Effect of a multifactorial intervention on mortality in type 2 diabetes. N Engl J Med 2008;358:580-91.

[15] Gaede P, Valentine WJ, Palmer AJ, et al. Cost-effectiveness of intensified versus conventional multifactorial intervention in type 2 diabetes: results and projections from the Steno-2 study. Diabetes Care 2008;31:1510-5. 